Article

\title{
Aesthetic Preference as Starting Point for Citizen Dialogues on Urban Design: Stories from Hammarkullen, Gothenburg
}

\author{
Brita Fladvad Nielsen ${ }^{1, *}$, Ruth Woods ${ }^{2}$ and Wenche Lerme ${ }^{3}$ \\ ${ }^{1}$ Department of Architecture and Planning, Norwegian University of Science and Technology, 7491 Trondheim, Norway; \\ E-Mail: brita.nielsen@ntnu.no \\ 2 Department of Interdisciplinary Studies of Culture, Norwegian University of Science and Technology, 7491 Trondheim, \\ Norway; E-Mail: ruth.woods@ntnu.no \\ ${ }^{3}$ City of Gothenburg, Angered City District Administration, 42421 Angered, Sweden; \\ E-Mail: wenche.lerme@angered.goteborg.se \\ * Corresponding author
}

Submitted: 28 June 2018 | Accepted: 28 September | Published: 24 January 2019

\begin{abstract}
This article sets out to describe the role of aesthetics in citizen dialogues during the upgrading of a local swimming pool in Hammarkullen, Gothenburg. The swimming pool became an important project because of its role in a larger neighbourhood renovation project that allowed the municipality to focus on citizen engagement and inclusion. The engagement process showed the importance of the local swimming pool for a marginalized group of women of Somali origin, and a decision was made to keep the swimming pool instead of demolishing it. This led to collaboration between project coordinators, the Public Art Agency, an artist and an architect. Individual qualitative interviews focusing on storytelling were undertaken with key stakeholders. The findings show that aesthetic quality mediated the communicative processes between project coordinators and citizens. Art in public space is more than just aesthetics or something to look at; art provokes a wide variety of responses and artists use a variety of means to engage with their public and creating dialogue. Yet the project managers failed to consider the creative process of the architect and her perspective on aesthetic quality and building functionality. Stakeholders take different stances to whether aesthetic quality can be a way of grounding, communicating and evolving, or whether it is a matter of beauty where the artist or architect takes the lead. While the project coordinators affirm sameness, different understandings of aesthetic quality actively negotiate social differences. Inability to consider creative practices' work processes in relation to citizen dialogue can result in conflicts between art, architecture and governance during the transformation of a neighbourhood.
\end{abstract}

\section{Keywords}

aesthetics; architecture; citizen involvement; creativity; public art; storytelling; swimming pool; urban design; urban upgrading

\section{Issue}

This article is part of the issue "The Transformative Power of Urban Planning through Social Innovation", edited by Torill Nyseth (UiT, The Arctic University of Norway, Norway) and Abdelillah Hamdouch (University of Tours, France).

(C) 2019 by the authors; licensee Cogitatio (Lisbon, Portugal). This article is licensed under a Creative Commons Attribution 4.0 International License (CC BY).

\section{Introduction}

Planning authorities within city municipalities increasingly take the role of negotiators between private stakeholders rather than as managers of urban design. This is largely due to the increased need of integrating lib- eralized service distributors such as energy utilities into planning, and the inability of planning processes to act holistically once implementation begins (Campbell, 1996; Juhasz-Nagy et al., 2017; Nielsen, Juhasz-Nagy, Wyckmans, \& Andresen, 2016). Within this technically focused era of integrated planning, municipalities ask for 
improved ways to engage citizens and implement citizen's needs into multi-stakeholder processes (Eising \& Jabko, 2001). Public art, which has a long history within urban environments (Craske, 1997), is being reconsidered in terms how it can be applied to achieve public engagement. At the same time, its development is also characterised by multiple stakeholders and in need of effective dialogue.

Our research question examines how public art and aesthetic quality influence dialogue between citizens, urban planners, project coordinators, artist and architect. The goal of this study was to learn from its impact on social innovation in neighbourhood upgrading and planning.

The starting point for investigating this is the case of a local swimming pool in the Hamarkullen district of Gothenburg. The project coordinators from the EU-Gugle programme for retrofitting and energy upgrading city districts had chosen to use funding from the programme to engage their citizens. The importance of socioeconomic targets and sustainability introduced the issue of what the local swimming pool meant to a marginalized group of women of Somali origin. In urban environments selected for upgrading in Sweden, it is common that large percentages of the inhabitants have relatively low-incomes and are first-generation citizens. Due to these interdependencies, it becomes important to investigate how participation, engagement, ownership and inclusion can be stimulated during the neighbourhood planning process. The citizen dialogue in this case led to the political decision to keep the swimming; and a resulting redesign collaboration of EU-Gugle project coordinators, the Public Art Agency, an artist and an architect. Building on the ideas from the dialogue with the local women, the artist decided to bring an art installation based on green plants into the swimming pool; somewhere "they could look out but not be seen" and be connected with the green space outside. However, the art intervention conflicted with the architect's standpoint towards functional design, and a significant disagreement about what the aesthetic outcome in this case should be.

By interviewing the stakeholders, we identify and discuss the different stories told about the design and implementation process. The stories, when seen together, reveal new insights about how aesthetic qualities played a key role in shaping dialogue between project coordinators and citizens during the neighbourhood upgrade. The stories further exemplify how working closely with citizens and giving emphasis to their experience may lead to surprising design preferences that question the 'for whom' the redesign should be. We wish by this to contribute to the improvement of existing citizen inclusion practices; by exemplifying how public art and aesthetic quality as an entrance to citizen dialogues can be better managed within the planning process; and, to learn from its impact on social innovation in neighbourhood upgrading and planning.

\section{Theory of Aesthetics, Art and Inclusion in Urban Planning}

How can aesthetics be approached in the frame of inclusion? First, we need to understand that there are different perspectives on aesthetic qualities. They are often associated with the appreciation of art, but despite this, aesthetic qualities are not easily defined because art can provoke a wealth of associations. Importantly, aesthetic quality is not just about appreciation because we may not like what is being contemplated and this may even be the point of including aesthetic qualities. They can be used to provoke rather than to sooth and attract. An effective way of defining aesthetic quality is to contrast it with what it is not. It is often understood as contrasting with practical qualities associated with moral, scientific and economic factors (Dickie, 1974). Despite the difficulties in pinning down what aesthetic quality is, it cannot easily be ignored. "Aesthetics" Danto suggests are defined by the way "things show themselves", and that as long as there are visible differences in the way things look, "aesthetics are inescapable" (Danto, 1981). If we avoid connecting aesthetic quality to the visual senses, then aesthetic experience becomes broader and less dogmatic. Defining beauty, taste and the role of the senses in relation to reason guided the development of aesthetic theory and found its form in the writings of Baumgarten as "the science of sensory knowledge" (Baumgarten, 1750). In which a correlation between a stringency of knowledge and reason is understood as existing alongside the more diffuse realms of sensation and taste (Baumgarten \& Schweizer, 1988; Woods, 2012). When the nature of aesthetic quality was first analysed during the 18th century, it was maintained that the "point of art was the provision of visual pleasure" (Danto, 2005). There is a close association between the appreciation of art and aesthetic theory, but aesthetic appreciation does not have to be tied to art, objects in general or to a particular kind of taste. Prior to the theories of Fredrich Schelling in the early 19th century, aesthetic qualities were associated with a number of different phenomena, including nature, and not particularly art (Lübcke, 2010). Artists such as Duchamp challenged this idea in the early 20th century, making it clear that art could exist that was philosophically independent of aesthetic theory. Artworks no longer had to be beautiful or aesthetically pleasing. Danto proposes that something becomes art, "when it is about something" (Danto, 2005). Aesthetic qualities do not define an object as a work of art; instead, they help us understand the point of a work of art. Aesthetic qualities can be used to make a statement about needs, support cultural preferences and thereby support inclusion. The use of aesthetic qualities to understand inclusive process is not well established. Lossau and Stevens (Lossau \& Stevens, 2014) are critical of an analysis of public art from an aesthetic starting point, they suggest that it limits people's encounters to passive reception, and focuses on what the artist, cu- 
rator or sponsor intended. This misconception is relating aesthetic quality to passive visual appreciation. When aesthetic quality is connected to a broader set of sensory responses (Baumgarten \& Schweizer, 1988) including, taste, smell, sound, temperature and texture, it offers a more active understanding of the environment. An aesthetic analysis places us within an environment that we do not just see but respond to based on the senses that are activated. It also allows for different cultural interpretations of aesthetic qualities avoiding a predefined set of western codes and values (Rampley, 2005). The object centred focus, which has characterised Western analysis of art and aesthetic quality, becomes less important and the potential for including diverse forms and format open up (Coote $\&$ Shelton, 1992).

The role of public green spaces in fostering social inclusion of different cultures has been studied (Bowler, Buyung-Ali, Knight, \& Pullin, 2010; Seeland, Dübendorfer, \& Hansmann, 2009); showing that green spaces can be an important link across cultures; adding to the idea that appropriate use of aesthetic qualities can foster dialogue. The idea of green spaces fostering inclusion also supports the concept of making sense of aesthetic qualities as part of a broader set of sensory responses, as discussed above.

Aesthetic qualities can be used to influence the public, and to understand the intentions of the makers. Regarding inclusion, public art has a long tradition of carrying the agency of inclusion in urban planning and architecture (Sharp, Pollock, \& Paddison, 2005); while architecture has been shown to also have the ability to be political and a "frontier of cultural policy" (NitzanShiftan, 2005). Concern for the intention of the maker has moved on from the traditional "artworld" dominance of artists, curators and sponsors (Becker, 2008; Dickie, 1974; Silvers, 2003). The modernist conception of art where autonomous artists required freedom of expression (Malcolm, 1997) has been criticised for its inability to meet public needs (Gablik, 1995) and the monumental and aesthetic interventions in public art no longer dominate contemporary urban planning. Collaborative practices first established during the 1960s started the process of breaking down the distance between the artist and the public. Making the artist a "cultural-artistic service provider"(Kwon, 2002) rather than an aesthetic expert. This shift has also changed the understanding of who the public is and the role that they play. From being primarily an audience who is informed and educated, "the public is being asked to inform and educate the public art process" (Gee, 1995).

Rose and Massey (2003) suggest that although artworks are almost always situated in a place. A work of art that is without a relationship to an audience cannot be defined as a "public" work of art at all (Rose \& Massey, 2003). Sharp et al. (2005) argue that "the processes through which artworks become installed into the urban fabric are critical to the successful development of inclusion". However, they also explain that "public art can be read in different ways and that its uses to beautify the city or celebrate its reimagineering do not necessarily enjoy universal consensus. In this respect, public art is no different from art in general where matters of taste and preference become paramount". The current perspective suggests that "the production of aesthetics" is an idea that makes citizens and producers of art become a part of the process. Public art in the Scandinavian context resonates with the Scandinavian origin of co-design, where participatory design during the 60s was rooted in work with trade unions (Ehn, 2017). Scandinavian researchers and trade unions developed the workoriented approach to democratization of design and codesign in the Scandinavian tradition "includes all stakeholders of an issue not just the users, throughout the entire process from research to implementation" (Szebeko \& Tan, 2010). This tradition- of co designing public space offers a particular place for art, in which the role of the artist easily can end up being pre-defined, with the artist acting in the name of all stakeholders' interests. However, art and making art can also be divisive; with experience of urban regeneration and the process of revival potentially causing social divisions leading to what Mitchell (2000) described as "culture wars". Promotion and deployment of the arts can still generate tensions (Lees \& Melhuish, 2015), because an idealistic and essentialised sense of place and community when combined with an unspoken expectation for what the arts and culture can do, can be uncritical or imply "minimum risk". The ability of public art to ensure democratic involvement in public places is a challenge because democracy is often contested, belonging to no single political perspective or group (Deutsche, 1992).

The presence of a public art project, helps to give a building upgrade, for example in an inner city neighbourhood, "democratic legitimacy". Terms like "public", and "art" are often associated with universality, openness and inclusion, but in fact they may be supporting the exclusionary rights of property control and disciplinary power because art needs protecting (Deutsche, 1992), often from those that it is intended for. Cultural planning therefore raises the question of "culture for whom?" (Bianchini \& Parkinson, 1993; Boyle \& Hughes, 1991) This question of "art for whom" is particularly challenging in multicultural societies in modern cities. The question about "culture for whom" can be seen in parallel to the emergence of integration focused urban planning schemes, for example, the currently popular smart city model, in which the city might is seen as a "production of consensus" (Swyngedouw, 2009). When models like this are applied uncritically, questions arise about what it means to be a local voice, and is it possible to resist the dominating groups' visions (Balibrea, 2001).

Public art's goal is to engage with its public and the use and understanding of aesthetic qualities is not always primary. Art provokes a wide variety of responses and artists use a variety of means to engage with their public. This analysis of the role of aesthetic qualities of- 
fers insight into how public art functions within a public space, and aesthetic theory helps to differentiate the public art from other aspects found within the physical social context (Woods, 2012). Importantly, the broad sensory definition means the analysis is not limited to the beautiful or what can be seen and as we will show this seems particularly relevant in the case of the swimming pool in Hamarkullen. Where the Somali women emphasized the importance of other qualities associated with the physical environment in and around water, and where what we see is related to privacy and what it means to be a woman in the community.

\section{About the Public Swimming Pool and Stakeholders in Hammarkullen}

At the centre of this study is the upgrading of the Hamarkullen swimming pool. Hamarkullen is located in Angered, one of ten districts in Gothenburg, northeast of the town centre. The Hammarkullen neighbourhood was chosen for an energy upgrade by the EU-Gugle programme. EU-Gugle is an EU funded program that aims to demonstrate the feasibility of nearly-zero energy building renovation models. The intention is to encourage Europe-wide replication in smart cities and communities by 2020 . In Gothenburg, Sweden, the funding was used to address social and economic challenges in the Hammarkullen neighbourhood. The Swedish image as a welfare society is challenged by an increasing spatial concentration of poverties (Castell, 2016). In areas like Hammarkullen, some stakeholders assume that social problems and safety concerns may challenge participation.

The swimming pool became an important project because of its role in a larger renovation project that allowed the municipality to focus on citizen engagement. In addition to serving as a meeting-place for recreation, the swimming pool is important to schoolchildren and the women in Hammarkullen.

The first area plan proposed to close the local swimming pool, and a newer pool was to be built nearby. However, local women of Somali origin objected to this idea, and told the project coordinators from the EU-Gugle project that the swimming pool was a very important meeting place for them.

The key stakeholders in the planning phase were:

- A project coordinator in Angered City District (the district in which Hamarkullen is located) together with researchers from Research Institute Sweden (RISE);

- The Public Art Agency (Statens konstråd);

- An artist (working with the women in Hamarkullen from August 2016 to January 2017);

- An architect (hired in the beginning of 2017).

The project coordinators chose to involve the Public Art Agency and the agency hired an artist to engage citi- zens in upgrading the swimming pool instead of closing it. Next, an architect was hired to help implement the ideas developed by the artist.

\section{Method}

Using storytelling is seen as a way to create better design (Quesenbery \& Brooks, 2010) and is "closely related to the experience blueprint"(Brown, 2009), meaning that it can give us insights relevant to the (urban) design process. In particular, storytelling was perceived as appropriate to explore the roles related to aesthetic quality, which depend upon how each stakeholder experienced the aesthetic quality and its' role in the design process and final design. The public pool project represents such a design process and we hence chose to focus on storytelling through interviewing and analysis. A story is a meaning bearing unit, typically consisting of a beginning, middle and an end which are connected by a plot (Wende \& King, 2015). Scholars of various disciplines propose that stories can be analysed through their ingredients; for example perspectives, characters, context, imagery and language (Quesenbery \& Brooks, 2010) or strategies, barriers and goals (Jonassen \& HernandezSerrano, 2002). Using storytelling as a frame to understand multi-stakeholder actions can provide insight into each participants' experience independent from their professional background. Ideally, the women involved in the art project should have been interviewed as well, but they were not available to be interviewed.

Interviews in the Hamarkullen project were undertaken with the EU project coordinator, a representative for the Public Art Agency, the architect and the artist. We conducted all four interviews individually via Skype, and each took between 30 to 45 minutes. All four interviewees were involved in some way in implementing the public art project. The expectation was that they would offer relevant perspectives about the whole process, their own roles and insight into the roles of other participating stakeholders. The interviews took a semistructured narrative form, this included asking participants to describe how they experienced the public swimming pool project. Interviews were recorded, and analyses focused on the story told by each of the participants.

The interviews were coded using a "highlighting technique" in four stages: first, searching for "structures of experience", second by describing how structures are thematic of the phenomenon (aesthetics, art and citizens), third by searching for essential themes and, lastly, by explaining and interpreting essential and incidental themes. Things that "stand out" as relevant to the research question were selected, and then used to understand the broader narrative that included all of the stakeholders. In this study, the stories are identified as independent meaning bearers, and represented as holistically as possible in the narrative form of the interview. This is to offer the reader insight into how one story reframes the previous. Afterwards their differences in 
relation to the topics of aesthetics, art and citizen inclusion in multi-stakeholder city development are discussed. It is worth noting that the sequence of the interviews influenced interpretation of the stories and the researchers' reflection process following the interviews. This way of analysing is cumulative, acknowledging that the first story leads the researcher to preliminary conclusions, which are later reinterpreted to make room for new perspectives from the other stories. To highlight this perception, the interviews are presented in chronological order in the findings section.

\section{Findings}

Three main stories were identified from the four interviews. The stories told during interviews of the EU project coordinator and the Public Art Agency have been combined into one during analysis because there were strong similarities.

\section{The Story about Aesthetic Quality and Inclusion}

The project coordinator and the public art agency participant both mentioned several times that their goal was inclusion. They say their aim was to increase knowledge about the significance of the Hammarbadet (swimming pool) and the symbolic value for Hammarkullen and its users, and to include Hammarbadet's users in the renovation process and the design of the upgraded pool. During autumn 2015, several workshops were conducted with local women, and the importance of the swimming pool to a group of women with Somali origin was identified. These women receive small salaries for heavy labour. The women explained that their social situation prevented them from taking part in many activities in Gothenburg and Hammarkullen. A deep concern for this group of women was expressed throughout the interview with the project coordinator, who said: "These women do not feel secure in most public baths; this is the opposite of many men and younger citizens, who often also have other public arenas and meeting-places".

Small meetings were organised by the adaptation of their approach because the women had little trust in the society. They did not believe their needs and thoughts would be listened to.

During workshops, women shared their experiences and needs, wishes and dreams for the development of Hammarbadet as a meeting-place where everyone can come together. The swimming pool was as a central to their participation and feeling of ownership within the community. They also had very specific aesthetic preferences: the women had expressed and agreed on that they wanted Hammarbadet to be fresh, warm and soft, white and blue: "Blue like the sky, and white like the waves and the foam on the waves", recalled the Project coordinator from meetings with the women had said.

Greenery and greenness were also important. The women also suggested greenery in the big windows in the pool that could act as protection from insight from outside, and along the walls in the entrance: "They said that they like the green-you feel happy-there is a lot of greenness in Somalia. The important thing is [what] the green and the blue tell about different places" (Project coordinator).

The workshops functioned as an inclusive process, and important knowledge was obtained about what the women do in the pool and their needs in terms of feeling safe (being able to see the outside without being seen).

The project coordinator and the Public Art agency participant explained that the proposed relocation of the swimming pool meant that a group of immigrant women would lose their meeting place. In the beginning, the focus of the EU-GUGLE programme and the renovation was on aesthetic quality and the building mass using the framework of EU-GUGLE, the project coordinator analysed how social benefits could be generated for the residential area by integrating the inhabitants, users and staff into the renovation process. They asked: what would make the women use the swimming pool? In a dialogue with the artist hired by the project coordinators, the women designed a swimming pool interior that was divided by green walls made up of moveable plants. However, the project coordinator and public art agency participant explained that this intervention with moveable plants collided with the architect's image of how the swimming pool should look. The architect did not agree with the citizens about which aesthetic qualities should be part of the built environment after renovation. Cooperation between the Public Art Agency Sweden and the artist became the bridge between the needs expressed by the women and the architect's preferences.

\section{The Story about Aesthetic Quality as Dialogue and Intervention}

The artist tells a story about how she sought to create communities both during the dialogue with the Somali women and through her artwork. She describes how she used dialogues about aesthetic qualities to understand the women's relationship with the building and surroundings.

She explained that first it is important to look at the place and the whole idea of the situation. She observes and talks to people to understand how they use the space, what they like and what they do not like, to find their desires and worries. Therefore, she travelled to the location for the public art, the swimming pool, and the neighbourhood to "look and feel". She asked different people to explain the context including workers from the swimming pool, and used that as a starting point to make a piece of art. She often said during the interview that she "talk[ed] a lot with people".

She learned that the public pool was the only public space where the women could act freely. The women regarded the public pool as a domestic space; the artist's project subsequently emphasized this idea of feeling at 
home. She was interested in how art influences communication. Even though she creates art with people, as an artist she makes the final art installation. The walls around the swimming pool are transparent; there is a close relationship between the forest outside and the swimming pool inside. She wanted to bring the forest into the building. She asked: do we act differently because of the surroundings? The art should influence and bring identity by bringing in the forest. "The art has no straight solution but listening and getting to know the context is the starting point for me, yet the (art) project needs to be interesting on its own", she said.

The women wanted to see outside, but they did not want to be seen. During a workshop, they talked about how they felt about the swimming pool. The artist then went back and forth between her home and Hamarkullen, and developed ideas before returning with her proposals. She said she normally meets different stakeholders involved and looks at the specific location and the general context, then works with the same stakeholders and the architects to gather insights. She sees the Public Art Agency as a key player in this process, ensuring that she could install the art the way it needed to be. She also spoke about the Botanical garden that was part of the final work, because she introduced Caribbean plants which would fit the specific conditions of the swimming pool. However, when "reality hit" the plants would not stand on the floor or hang where she wanted, and she was forced to adapt the installation. She says "reality hit" as if it was something common to her, that the creative work was often interrupted by external factors and needs to be adapted. The main goal was expressed when the artist explained that the greatest challenge to the adaptation phase was to create spaces. She emphasized that she needed room for different dimensions of plants to create a feeling of space and to change the original space. This was difficult due to regulations limiting how installations interrelate with safety, access and maintenance.

The art institution's role, in this case the Public Art Agency, was to provide the conditions necessary for the artist to create the art installation. With their support, she talked to the architects to make sure the installation had the space it needed. From the artists' viewpoint, the architect sees the art as a practical challenge. An art installation is demanding it needs maintenance. It is a live element.

The interview with the artist revealed her focus was to create temporary communities with people. Yet by this, she explained that she did not mean co-design in the way that the women decided the final aesthetic; instead, they contributed to her artistic practice and aesthetic choices through a dialogue about their relationship with the building, and the surroundings.

She viewed the Public Art Agency as central to her ability to complete her aesthetic vision in a way that gave the building and the women something that changed their relationship. The artist's focus was to work by "creating temporary communities with people, and let peo- ple create the project themselves by the way they move and relate in the space".

Yet she cautioned; the women were not interested in the aesthetic details. The resulting aesthetic quality was the artist's responsibility, and in the artists' view, it is not essential to include all the stakeholders when making decisions about the final details. The artist said: "They do not care so much about the colour of the pot".

The artist saw herself as separate both from the art and from the women in the final design, avoiding codesign advocates. The artist's job is instead to listen, and to bring in something else. To take what is interesting, not translate, but bring something new, "a new aesthetic", she said.

This artist had never worked so closely with a specific community before, and they made it interesting. These women were powerful, they saved the public pool, it will not be demolished. She believes that the Hammarkullen project added to the feeling of community and helped create the identity. She further argues that "Artists have a viewpoint that can bring a lot to the relationship".

The artist emphasized that she would have little impact without strong support from the Public Art Agency; and as such art can foster dialogue only if the context allows it to; and that a strong political anchoring is needed to bring different aesthetic understandings together.

\section{The Story about How a Beginning Can Limit Aesthetic and Inclusive Potential}

The first thing that the architect shared was her confusion caused by the amount of interested stakeholders in the project and the process. The architect revealed that she was included very late in the process, after the assessment of the women's needs. The architect was given a list of demands but had not been informed about the project's starting point; leaving her wondering if the swimming pool project required so many resources and attention. She was used to being a part of the ideation process at the start of a project, and this first stage was very important to her. The management of the process by the EU project coordinators and the Public Art Agency meant it challenged the architect's ability and desire to work creatively:

Hammarbadet is an existing building. In a renovation like this, our task as architects, in addition to taking responsibility for design, is to work with the given conditions and to ensure that today's requirements for function, accessibility and safety are met. Hammarbadet is a very small building; it is already a challenge to make it work with the current regulations. (Architect)

She explained that the Public Art Agency and the artist already had agreed on what the art should "do" and that citizens should feel included in the swimming pool. Following the agreement to use the pool as a symbol of inclusion, they presented the project leader and the 
artist's ideas to the architect as a list that was received more or less as a series of "demands in the form of a PowerPoint presentation". The starting point seemed wrong, she said, and the process both of decision-making and communication between stakeholders seemed very messy and unstructured. However, her aesthetic ambition for the building was a priority, and she did not think the building's potential had been achieved. She wanted the public pool to be different:

I would have for example wanted to add some warm wall colours in the public bath, to make it more appealing and create a different space. The artist's plant based installation is very nice, but she designed it thinking that the pool would have to be white. Conventional public pool surroundings.

It became clear during the interview that the architect had an aesthetic ambition that needed to be included from start to finish if it was to be achieved. A renegotiation could have included the architect from the start, and improved interventions instead of reducing them.

To make the lobby a meeting place is always one of our goals and for us a matter of course. In this case, the space was very limited. But it resulted in a small area with space for tables and a coffee machine. (Architect)

She suggested that the process involved too many stakeholders and too many researchers. The resulting project was characterised by a lack of agreement between the function of the building and requirements of the public art project. The form of the public art project being was pinned down too early, and resulted in the artist having to adjust her art. The architect thought that the final design was therefore less satisfying for everyone than what it could have been: "The artist's work didn't get the space it required to give the artist's idea the full impact. It was not possible in the existing areas".

\section{Discussion: Three Stories Seen Together}

The artist, EU project coordinator, and the Public Art Agency agreed that the artist's view should define the outcome. The artist's role was to create a dialogue with the women that would be manifested through an aesthetic intervention. The project coordinators and the Public Art Agency described conflict between the artist and the architect regarding the artists' aesthetic preferences. The interviews demonstrate that the architect's perspective was closer to the artist's than the project coordinator and the Public Art agency believed. The artist and architect tell a story about compromise between the function of the building and the role of the public art installation; but the coordination of stakeholders and decisionmaking limited the aesthetic impact for them both.

The interview with the EU project coordinator and the Public Art Agency stressed the project coordinator's interest in the social benefit of renovation of the built environment, and that questions about upgrading and aesthetic quality should be placed within a social context. They emphasized that the overarching goal was to include the women in a dialogue on aesthetic quality and to show how their preferences could be a way to ask, "who do we design for?" For the women using the pool the aesthetic qualities found in the pool should not only please the eye, they should protect and nurture communication. The public art they required should build upon existing sensory experiences of water, warmth and female companionship. The dialogue and connection with the citizens were central and a goal in itself from the very beginning for the project coordinators. If this had been communicated well enough and if the architect had been included from the starting point, perhaps both the process and the end result in terms of the physical intervention would have been closer to the aesthetic "ideal" of both the artist and architect? The portrayal of the architect in the first story, told by the EU coordinator and the Public Art Agency, missed the actuality that her ambitions and goals were very similar to the artist. The architect needed the same open frame for dialogue and creativity as the artist from the beginning. She also expressed that she was responsible for the functionality of the building. If the goal was inclusion, the architect believed that the project coordinators could have established a wider framework that considered the building's potential for physical and functional changes within building regulations. For an architect as for other practitioners following a design process, a starting point with end-user insights and creative idea generation should be an open one, and not defined by strict 'demands' to the creative practitioners; in this case the artist and the architect.

The architect was held responsible for not translating the input from the women and the artist into the final result; the artist saw that the translation had happened before the architect came into the project. The artist understood that the functionality of the building was the responsibility of the architect and hence there is a mitigation in her story. Interviews with the EU project coordinator, the Public Art Agency and the artist implied that the "primary story" was that the women using the pool wanted one thing, while the architect wanted something else. The architect's story conflicted with their view. In this story, what "the women" wanted was translated for them and then presented by the project coordinator. This made it difficult to generate ideas based on user insights while also taking into account regulatory framework. As architects, they had to follow the requirements for function, accessibility and safety.

\section{Aesthetics, Meaning and Communication}

An analysis of the use and understanding of aesthetic qualities provides a way to access the role of public art within a public space. Aesthetic quality was most noticeable as a term in the artists' story. When the artist 
applied the word "aesthetics" the artists' work became a tool for dialogue. If aesthetic quality provided a way of communicating, it could explain some of the misunderstandings between the stakeholders. A discussion on what public art and aesthetic quality "does" is missing from the collaboration between the EU project coordinator, Public Art Agency, artist and architect. While the starting point for the exploration of the Hamarkullen pool project was to establish how understanding aesthetic quality would influence the process of renovation and inclusion, the three stories reveal broader issues. The EU project coordinator found that the needs of the citizens were not consistent with those initially assumed by the architects. The findings indicate that paying attention to aesthetic preferences and using this as a meeting point for dialogue, could provide insights into citizen group's experiences and influence the level of participation and ownership within the upgraded neighbourhood.

While theory related to how art includes or divides is extensive, we find little discussion about the role of aesthetic quality on the roles of artists in relation to other stakeholders in urban regeneration projects. This we believe is because of a misconception; aesthetics is commonly associated with visual appreciation. It is part of a passive relationship with the physical environment. We propose that aesthetics can be applied to a broader set of sensory responses (Baumgarten \& Schweizer, 1988), related to an active understanding and use of the physical environment. The sensory understanding also offers room for different interpretations of qualities within the physical environment, including taste, smell, sound, temperature and texture (all qualities found in the Hammarkullen pool). Different cultural interpretations of aesthetic qualities necessary in a community like Hammarkullen must avoid a predefined set of western codes and values. The "application" and perceptions of aesthetic qualities and their place within a core of creative practices, caught our interest. It is present in the different understandings of aesthetic qualities mentioned by the artist, architect and public art consultant and it is realised in the choices made by the artist based on the aesthetic preferences of the women from Hammarkullen. In these interpretations of aesthetics; buildings and art represent the formal and visual aesthetic fields, whilst water, plants and forests represent aesthetic qualities drawn from an active use and understanding of the physical environment promoted by the women of Hammarkullen.

While the architect focuses on what the design of a building can do for peoples' feeling of inclusion, the artist sees the process itself as the one building inclusion. The artist and architect include empathising with the citizens and their needs within the project. For the artist the dialogue with the women in this project is a goal in itself, while for the architect the function of the building and the larger impact of the process on the city district is also important. Sharp et al., explains that 'the contribution of public art to the re-inscription of local place has become commonplace through the work of artists and community groups, as well as by the state acting through local agencies mindful of the agenda of inclusion. This builds upon an idea of community art established during the 1960 s, as "listener-centered", ideally with the artist involved with the community and in dialogue with the audience (Gablik, 1995). However, the EU coordinator and Public Art Agency when focusing on the community dialogue missed the importance of the architects' ability to influence aesthetic potential and only focused on the artist-state relationship. This reveals the danger of applying public art projects as "symbolic" capital identified by earlier research. It further shows that there is a danger of listening to only one story in urban planning projects. Although they seemed to be in unison, numerous stories were involved. If dialogue was the aim of involving the artist, this symbolic act was not shared with all stakeholders. This way of using art symbolically but without influencing socioeconomic goals in a material manner has been extensively covered by research; leaving a question of whether the Public Art Agency and the researchers in RISE could have made a more conscious effort to move beyond this:

The intention is to activate the audience allowing them to become participants or collaborator. Yet the number of projects where this actually occurs seems limited and the capacity of public art to foster inclusion is at best partial, addressing symbolic rather than material needs. (Sharp et al., 2005)

Uneven power relations mean that public art has become an unwitting agent in the over privileging of cultural justice at the expense of socioeconomic redistribution. There would seem to be an exaggerated faith in the influence of public art on economic regeneration, the massive symbolism of works like the "Angel of the North" has led to an over optimistic view of what public art can do. Which is itself part of an over economistic interpretation of the meaning of urban citizenship. A challenge is also that it can be too easy to focus disproportionately on the more spectacular, particularly the iconic, and its ability to re-inscribe place. A blinkered gaze risks the failure to identify the different scales at which public art has come into play, just as it tends to give emphasis to particular representations of it (Sharp et al., 2005). The majority of public art projects are like the Hammarkullen swimming pool on a smaller less visible and less iconic scale. Again, this points to the perception of other aesthetic qualities. When art rarely achieves massive iconic visibility, other sensory qualities on a more intimate social scale can support its role within the public space.

Interestingly while the artist in the story is raising radical questions, the architect initially comes through as having a rigid perception of aesthetic quality; representing a conformist aesthetic ideal. However, the artist mitigates this view by explaining that the architect's preference may also have to do with practical concerns; mean- 
ing that the architect may have a larger responsibility for the functional aspects of the final design. There is therefore a division of responsibilities affecting stakeholders' decision-making and relationship between this decision making and knowledge transfer. Yet, when speaking to the architect, it becomes clear that it may be the EU project coordinators way of managing the collaboration process between the architect and the artist; not taking into account the creative process of the architect that actually made communication difficult. Division of responsibilities is a decision made by the coordinators and in this case, there was a crossover of methods and aims. The architect's aesthetic ambitions are actually very high, and she sought lasting change that would result in a feeling of inclusion within the built environment and 'not only' during the process.

\section{Conclusions}

The stories show that aesthetic quality and public art effectively opens up dialogues between citizens and implementing stakeholders; yet it seems as if project coordinators, and also the artist, at some point start speaking on behalf of the included women instead of keeping them in the process also when the project moves towards implementation. We introduced this article by explaining the inability of planning processes to act holistically once implementation begins; and this project ran into the same difficulty despite the work to create dialogue at the beginning. By presenting the needs of the women to the architect without them being present, they may hinder the "true" co-creation and the possibility of the architect contributing to the collective creative process. Could they have included the women and the architect from start to finish? The choice of approaches presented here centred on aesthetic quality and provides insights into how the stakeholders' view of the role of aesthetic quality can be of importance when understanding how to create dialogue in practice.

A conclusion from the three stories identified may be that the creative processes of artists and architects could benefit from considering their professional understanding of aesthetics and the working process when designing citizen consultation plans; before determining the scope of a building or urban design project. In addition, it could put the aesthetic practitioners in an empowered role within this project: something that could have augmented the impact and avoided the project falling into the category of "symbolic" public art with a predefined purpose. Both the artist and architect want to think about aesthetics with a personal relationship, something that they see evolving from personal meetings with the women and by immersing themselves personally in the context. The artist brings in something new to the relationship between the space and the people, while the architect wanted to modify the building in a functional way. Modern city development and design processes need to be thought of as collaborative; without silos separat- ing the disciplines. In Hammarkullen, assumptions were made about the role of the architect, and there was a lack of understanding between the disciplines. If we are going to avoid silo-thinking, then the stories must be refined to create methods to support integrated urban planning. Such efforts can maximize the impact of aesthetic quality dialogues on citizen inclusion, participation and urban design. The creative practitioners should be mutually invested in the first citizen-centred process and discuss aesthetic outcomes and responsibilities, avoiding 'consensus-seeking' and compromise. The artist and the architect both agreed on these goals. The artist desires to remain autonomous despite combining this need with dialogue and process of inclusion. This implies that securing aesthetic quality remains within the domain of the artist, at the same time the negotiations that took place imply that the artist's autonomy is not intact and requires constant re-evaluation.

Can this case about a public swimming pool inform citizen inclusion processes on the larger scale desired in city planning, without losing its critical and interventionist style of "changing aesthetics"? The project shows the need to consider aesthetic qualities in a broader sense and offer support and explanation to studies that identify the socially including function of green space. The story does add substance to the worry that "those who see public art as leading to the enhancement of community" are missing the point because they "presume that the task of democracy is to settle, rather than sustain, conflict" (Sharp et al., 2005). However, even though the architect's story was ignored during the process, the public art and the open view on aesthetic quality did create dialogue and helped save the pool from demolition. We also want to avoid the pitfall where "community can be a dangerous construct if it hides the process of making individuals and groups behind the façade of its inclusionary rhetoric" (Docherty, Goodlad, \& Paddison, 2001). Participatory processes have often been criticized for being political and neo colonialist by nature. We can conclude that the work of the artist in the public pool project challenged this purpose of participation and inclusion. Using Milton Keynes as an example, Rose and Massey (2003) argue that "public art should be understood as an intervention into social space that will actively help to produce that space through a negotiation of social difference, rather than by affirming sameness" and is seen as the opposite of consensual interaction. From the perspective of broad literature on what "public art" should mean, the public swimming pool project is not controversial; yet the stories about the conflict between architect and artist do highlight a fundamental barrier to how local groups and particularly the non-privileged groups can begin to identify themselves with urban regeneration projects. Acknowledging that "it is doubtful as to whether local issues are given full rein when broader economic ones appear to be so much more immediate" (Miles \& Paddison, 2005), the stories from Hamarkullen and a discussion about aesthetics as a meeting point may 
represent something that could be replicable and indeed scalable. If we allow for the idea that the regeneration should also include the handing over of ideals about aesthetic quality to the communities living in marginalized areas, we may be able to design new concepts for what these neighbourhoods could look like and establish the use of aesthetic qualities as a larger dialogue.

\section{Acknowledgements}

This study is a part of data gathering for the PI-SEC research project at NTNU, funded by the Norwegian Research Council. We are grateful for the participation from the Public Art Agency, the artist, RISE architects and the project coordinator.

\section{Conflict of Interests}

The authors declare no conflict of interests.

\section{References}

Balibrea, M. P. (2001). Urbanism, culture and the postindustrial city: Challenging the 'Barcelona model'. Journal of Spanish Cultural Studies, 2(2), 187-210.

Baumgarten, A. G. (1750). Aesthetica (2 volumes). Frankfurt ad Oder: Olms.

Baumgarten, A. G., \& Schweizer, H. R. (1988). Theoretische Ästhetik: Die grundlegenden Abschnitte aus der "Aesthetica" (1750/58). Lateinisch-Deutsch [Theoretical Aesthetics: the basic parts of "Aesthetica" (1750/58) Latin-Deutsch]. Hamburg: Felix Meiner Verlag.

Becker, H. S. (2008). Art worlds. Updated and expanded. Berkeley, CA: University of California Press.

Bianchini, F., \& Parkinson, M. (1993). Cultural policy and urban regeneration: The West European experience. Manchester University Press.

Bowler, D. E., Buyung-Ali, L., Knight, T. M., \& Pullin, A. S. (2010). Urban greening to cool towns and cities: A systematic review of the empirical evidence. Landscape and Urban Planning, 97(3), 147-155.

Boyle, M., \& Hughes, G. (1991). The politics of the representation of 'the real': Discourses from the Left on Glasgow's role as European city of culture 1990. Area, 23(3), 217-228.

Brown, T. (2009). Change by design. New York: HaperCollins.

Campbell, S. (1996). Green cities, growing cities, just cities? Urban planning and the contradictions of sustainable development. Journal of the American Planning Association, 62(3), 296-312.

Castell, P. (2016). Institutional framing of citizen initiatives: A challenge for advancing public participation in Sweden. International Planning Studies, 21(4), 305-316.

Coote, J., \& Shelton, A. (1992). Anthropology, art, and aesthetics. Oxford: Oxford University Press.
Craske, M. (1997). Art in Europe, 1700-1830: A history of the visual arts in an era of unprecedented urban economic growth (Vol. 110). Oxford: Oxford University Press Oxford.

Danto, A. C. (1981). The transfiguration of the commonplace: A philosophy of art. Cambridge, MA: Harvard University Press.

Danto, A. C. (2005). The philosophical disenfranchisement of art. New York, NY: Columbia University Press.

Deutsche, R. (1992). Art and public space: Questions of democracy. Social Text, 33, 34-53.

Dickie, G. (1974). Art and the aesthetic: An institutional analysis. Itacha, NY: Cornell University Press.

Docherty, I., Goodlad, R., \& Paddison, R. (2001). Civic culture, community and citizen participation in contrasting neighbourhoods. Urban Studies, 38(12), 2225-2250.

Ehn, P. (2017). Scandinavian design: On participation and skill. In D. Shuler \& A. Namioka (Eds.), Participatory design: Principles and practices (pp. 41-77). Hillsdale, NJ: CRC Press.

Eising, R., \& Jabko, N. (2001). Moving targets: National interests and electricity liberalization in the European Union. Comparative Political Studies, 34(7), 742-767.

Gablik, S. (1995). Connective aesthetics: Art after individualism. In S. Lacy (Ed.), Mapping the terrain: New genre public art (p. 74). Washigton, DC: Bay Press.

Gee, M. (1995). Yes in My Front Yard: Public participation in the public art process. High Performance Magazine, 18(1/2), 60-60.

Jonassen, D. H., \& Hernandez-Serrano, J. (2002). Casebased reasoning and instructional design: Using stories to support problem solving. Educational Technology Research and Development, 50(2), 65-77.

Juhasz-Nagy, E., Lindkvist, C. M., Nielsen, B. F., Lobaccaro, G., Neumann, H.-M., \& Wyckmans, A. (2017). Holistic planning approaches with common ground. Paper presented at the Urban Transitions Pathways Symposium.

Kwon, M. (2002). One place after another. Site-specific art and locational identity. Cambridge, MA: MIT Press. Retrieved from monoskop.org/images/d/d3/ Kwon_Miwon_One_Place_after_Another_Site-Spe cific_Art_and_Locational_Identity.pdf

Lees, L., \& Melhuish, C. (2015). Arts-led regeneration in the UK: The rhetoric and the evidence on urban social inclusion. European Urban and Regional Studies, 22(3), 242-260.

Lossau, J., \& Stevens, Q. (2014). The uses of art in public space. Routledge.

Lübcke, P. (2010). Politikens filosofileksikon [The philosophy encyclopedia of philosophy]. Copenhagen: Politikkens forlag A/S: Politikens forlag København.

Malcolm, M. (1997). Art space and the city: Public art and urban features. New York, NY: Routledge.

Miles, S., \& Paddison, R. (2005). Introduction: The rise and rise of culture-led urban regeneration. London: Sage. 
Mitchell, D. (2000). Cultural geography: A critical introduction. Oxford: Blackwell.

Nielsen, B. F., Juhasz-Nagy, E., Wyckmans, A., \& Andresen, I. (2016). Planning instruments for smart energy communities (Report 2.1). Norway: NTNU.

Nitzan-Shiftan, A. (2005). Capital city or spiritual center? The politics of architecture in post-1967 Jerusalem. Cities, 22(3), 229-240.

Quesenbery, W., \& Brooks, K. (2010). Storytelling for user experience: Crafting stories for better design. Rosenfeld Media.

Rampley, M. (2005). Art history and cultural difference: Alfred Gell's anthropology of art. Art History, 28(4), 524-551.

Rose, G., \& Massey, D. (2003). Personal views: Public art research project. Artpoint. Milton Keynes: Open University.

Seeland, K., Dübendorfer, S., \& Hansmann, R. (2009). Making friends in Zurich's urban forests and parks: The role of public green space for social inclusion of youths from different cultures. Forest Policy and Eco- nomics, 11(1), 10-17.

Sharp, J., Pollock, V., \& Paddison, R. (2005). Just art for a just city: Public art and social inclusion in urban regeneration. Urban Studies, 42(5/6), 1001-1023.

Silvers, A. (2003). artworld. In D. Cooper, J. Margolis, \& C. Sartwell (Eds.), A companion to aesthetics (p. 155). Oxford: Blackwell.

Swyngedouw, E. (2009). The antinomies of the postpolitical city: In search of a democratic politics of environmental production. International Journal of Urban and Regional Research, 33(3), 601-620.

Szebeko, D., \& Tan, L. (2010). Co-designing for society. Australasian Medical Journal, 3(9), 580.

Wende, E., \& King, G. (2015). Exploring storytelling for relationship building in offshore outsourced projects: An action research investigation. Paper presented at the 48th Hawaii International Conference on System Sciences (HICSS).

Woods, R. (2012). Shopping with art: How art creates its role in public places (Unpublished Doctoral dissertation). Retrieved from brage.bibsys.no

\section{About the Authors}
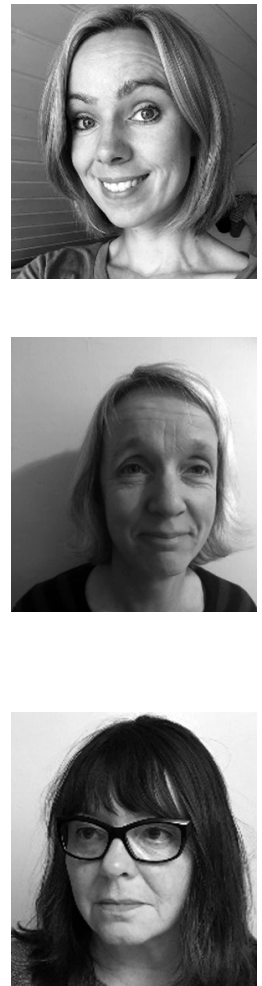

Brita Fladvad Nielsen is a Post-Doctoral Researcher at the Norwegian University of Science and Technology (NTNU). She holds a PhD in design methods and a Master of Technology degree in industrial design. She applies design-thinking and visual approaches for making sense of the complexity in smart city projects. She has worked and researched the human-centred aspects and private/public collaborations in energy related issues, in the Norwegian context but also in humanitarian relief and development settings, as well as design for refugees in Latin America and Sub-Saharan Africa.

Ruth Woods is an Anthropologist with a background in Fine Arts. After completing a PhD on public art in 2012 at the Faculty of Architecture and Design at NTNU, she moved into working with architecture and technology at SINTEF Building and Infrastructure in Trondheim. Her main interest is the users' relationship with the physical environment. Woods has been working with living labs since 2015 . First as the in-house anthropologist in ZEB living lab and now as a postdoctoral fellow at the Department of interdisciplinary studies of culture, NTNU with responsibility for living labs at the Research centre for zero emission neighbourhoods in smart cities. Urban design and participatory practices are an important part of this work.

Wenche Lerme, Architect SAR/MSA, is an Urban Planner and Development Manager in the City of Gothenburg, Angered City District Administration. Her work and interests focus on driving development issues in a socio spatial context for reducing segregation and housing shortage, and to reach equal conditions and environments for people in the city. She has worked with questions about housing and functional integration and accessibility to the city for people with disabilities and been project leader for several art- and culture projects, and exhibitions. She is project leader for the City of Gothenburg in the EU-project EU-GUGLE. 